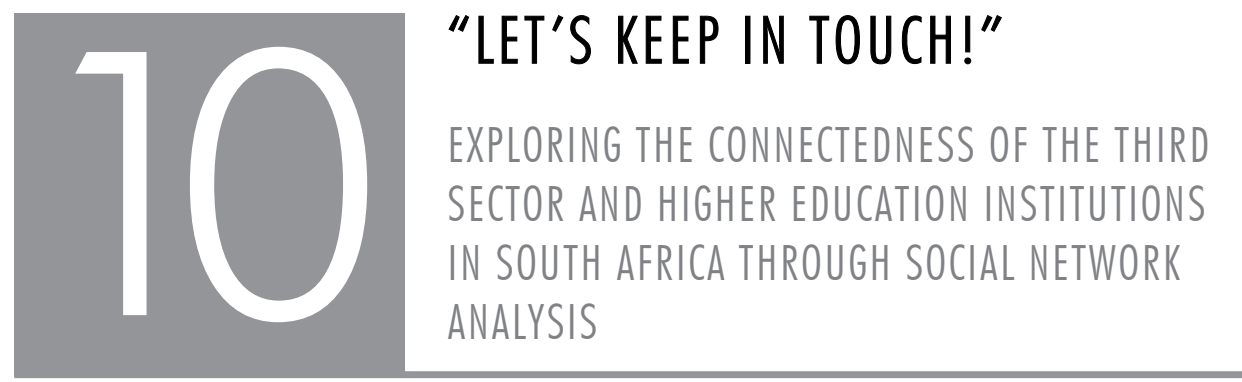

\title{
Elene Cloete
}

\section{ABSTRACT}

As higher education institutions become more invested in community engagement, they establish partnerships with third sector organisations. These partnerships result in an intricate web of social relations, or social networks, through which higher education institutions and the third sector can address challenges and needs collectively. Such collaboration not only raises the effectiveness of individual organisations, but also the success of community engagement initiatives. Additionally, scholars have found that social networking is an effective means to distribute knowledge resources among individual organisations. This chapter is concerned with the nature of these interorganisational networks, in particular those between the third sector and higher education institutions. To gain information on such networks, and subsequently gain a deeper understanding of third sector dynamics, this chapter proposes the method of social network analysis. By means of a case study, it is shown how social network analysis sheds an alternative light on the relations and degree of interaction between third sector organisations and higher education institutions. Such information can enable higher education institutions to evaluate their community engagement initiatives and subsequent position within the third sector. 


\section{CHAPTER $10 \cdot$ CLOETE}

\section{BACKGROUND}

At the 4 o'clock coffee break at the annual convention for local nonprofit, non-government and public organisations, attendees exchange their thoughts over the day's proceedings and the 'way forward'. They ponder over their role as third sector actors; they celebrate reached objectives, and compare their respective organisations' stumbling blocks. Parting statements range from "Can I have your card?" to "let's keep in touch!"

Whether consciously or unconsciously, these individuals are expanding their list of contacts; in essence, they are broadening their social network. According to Guo and Acar (2005), this is by no means uncommon among third sector organisations as they frequently network among one another to form alliances, collaborations and partnerships. In the process, organisations develop interorganisational networks through which they share knowledge and resources, and become more responsive, connected and creative (Gilchrist 2004). These interorganisational networks enable organisations to pursue shared goals, address common concerns and attain mutually beneficial ends (Kapucu 2005:35) - all of these providing more than enough reason for our third sector workers to exchange cards.

Interorganisational networks are intricate social systems, comprising a web of dynamic social relations. To analyse such relational dynamics, researchers can rely on social network analysis (SNA), a methodology derived from social network theory and focused on the interaction between persons, organisms, or organisations that are all active within a particular social context (Kenny, Kashy \& Cook 2006). Social network theorists typically interpret social systems as a network comprising actors and ties. An actor can be any defined entity, such as an individual, organisation, even country, whereas a tie represents the relationship between the different actors of a network (Ennis \& West 2012). Since SNA is primarily focused on the characteristics of relationships, it can help researchers gain a deeper understanding of interorganisational networks.

As in the case of South Africa, interorganisational networks among third sector organisations often include additional outside members, such as higher education institutions (HEls). In fact, these institutions prioritise community partnership building. This is in light of the Department of Higher Education's Education White Paper 3 (RSA DoE 1997) mandating HEls to become involved in their communities, demonstrate social responsibility and commit to the common good (Lazarus, Erasmus, Hendricks, Nduna \& Slamat 2008). Consequently HEls are increasingly becoming members of 


\section{EXPLORING THE CONNECTEDNESS OF THE THIRD SECTOR AND HIGHER EDUCATION INSTITUTIONS}

the third sector's interorganisational networks, and partaking in relational processes of sharing knowledge and resources.

Information pertaining to interorganisational networks is highly beneficial to HEls who want to understand, justify, and improve their role within the third sector. HEls can use such information to evaluate their community engagement strategies and, if need be, adjust their contribution to a particular third sector social network. As Lazarus et al (2008:62) argue: "Involvement through community engagement is a rather big investment". Research shedding light on the nature of such engagements and the relationships in which they are enmeshed is therefore greatly warranted. That being said, research pertaining to the interorganisational social networks among third sector organisations and HEls seems to be non-existent. How can we respond to this current gap and gain a deeper understanding of the social networks found between the third sector and higher education?

In what follows, I argue that SNA is an innovative method by which to understand the degree of interaction, collaboration, and consequently also knowledge sharing, between third sector organisations and higher education. Furthermore, SNA can shed light on the role of individuals within the third sector, deepen our understanding of how this sector functions, and also shed light on the role of HEls in communities. The rest of this chapter is divided in two sections. In the first section I briefly elaborate on SNA, discussing its analytical functions and its role within the context of interorganisational networks. In the second section I demonstrate how SNA can provide us with an alternative analysis to understand the interaction between nonprofit organisations (NPOs) from the third sector and HEls, in particular their levels of collaboration and knowledge sharing. Using three NPOs and one $\mathrm{HEl}$ from urban South Africa as case study, I illustrate how SNA depicts the structure of the network in question, and the centrality of individuals with regard to collaboration and resource sharing.

\section{SOCIAL NETWORK ANALYSIS}

Social network analysis for interorganisational application as well as the analysis thereof is relevant.

\subsection{Social network analysis for interorganisational networks}

Interorganisational networks are essential to the well-being of third sector organisations. According to Galaskiewicz, Bielefeld and Dowell (2006), the relationships and consequent network formed between organisations - that is interorganisational 
networking - have a direct influence on their individual performance. In fact, the manner in which third sector organisations are embedded in a larger system directly affects their survival rate (Uzzi 1997). Their survival is mostly tied to an NPO's dependency on funds and donations. In economic climates where funding is not necessarily expanding at the same rate as the societal needs NPOs attend to, these organisations find themselves, often competitively, stretched for funds (Eng, Liu \& Sekhon 2011). In response to this social and economic climate, NPOs collaborate with other organisations to coordinate services, collectively obtain resources, and deal with governmental agencies (Johnson, Honnold \& Stevens 2010:499). Forging innovative and increasingly complex linkages with one another provides these organisations with a sense of security.

The internal and social functioning of organisations, such as the above-mentioned collaboration strategies and interorganisational interaction, point toward a social dynamic worthy of scholarly attention (Fisher 1997). Such research will "enrich our understanding of local and translocal connections that enable and constrain flows of ideas, knowledge, funding and people" (Fisher 1997:441). Moreover, a greater in-depth understanding of the internal and network dynamics of third sector organisations challenges "reductionist views of NGOs as fixed and generalizable entities with essential characteristics" (Fisher 1997:442).

As a research method focused specifically on the relational dynamics of networks, SNA supplies both the researcher and third sector organisations with empirical data to describe and, if needed, alter their social relations with other organisations. Two studies in particular, those of Johnson et al (2010) and Moore, Eng and Daniel (2003), illustrate how SNA can be applied within the third sector. In their recent study Johnson et al (2010) explored the viability of SNA by introducing it to 52 NPOs, all within a bounded geographic area. Johnson et al (2010:495) show how NPOs who include SNA in their research agendas can "better compete for scarce resources, meet funding requirements and advance their interests through policy". These researchers conclude that SNA provided these NPOs with a deeper understanding of their particular interorganisational network. The NPOs got a sense of where they stand in relation to the fellow organisations, identified organisations who might be future partners, recognised which organisations within the network needed assistance, and which organisations within the network are best situated to supply them with information. Such information, Johnson et al (2010:509) argue, helps an organisation "negotiate a stronger position for itself within the network".

Whereas Johnson et al (2010) advocate for the use of SNA by third sector organisations, Moore et al (2003) illustrate how SNA can link the organisational 


\section{EXPLORING THE CONNECTEDNESS OF THE THIRD SECTOR AND HIGHER EDUCATION INSTITUTIONS}

qualities of the third sector with its outcomes. In reference to the $65 \mathrm{NGO}$ active during the 2000 Mozambique flood disaster, Moore et al (2003) investigated the correlation between effective aid distribution and the characteristics of these NGOs' organisational network. Since "the success of humanitarian aid operations ultimately depends on the ability of organisations to work together" (Moore et al 2003:316), learning more about the structure of these organisations' networks can inform aid administrators how best to distribute resources. Using primarily SNA's measures of centrality, Moore et al (2003) conclude that those organisations which have the highest degrees of centrality within their particular aid network reached the highest number of beneficiaries. The qualities of a third sector network, in particular with regard to measures of centrality, inform scholars and organisations alike on its communal effectiveness, accountability and impact.

Similar to Moore et al (2003) and Johnson et al (2010), Provan, Fish and Sydow (2007) accentuate the role of SNA in illuminating the dynamics of the third sector. Provan, Veazie, Staten and Teufel-Shone (2005), however, extend this view to include public organisations. They regard such interaction as being quite logical since collaboration allows different organisations to "draw on the broad range of resources and expertise provided by the other organisations in the network and subsequently improve the well-being of their communities" (Provan et al 2005:603). These authors recommend SNA as an appropriate method to understand interorganisational interaction, specifically between community and public organisations. Furthermore, as Provan et al (2005:604) argue, SNA can show managers "where their organization fits within the structure of the network, based not just on their own perceptions, but also on the experience of the other network participants". Knowledge pertaining to the inherent dynamics of organisational networks allows managers to adjust their individual, as well as organisations', positions to improve their impact and address communal needs better.

As public institutions increasingly engaged in partnership building and community engagement activities, South African HEls fall comfortably within Provan et al's (2005) range of organisational partnerships. Additionally, seminal authors on higher education community engagement, Bringle, Clayton and Price (2009:3), state that "civic engagement and service learning activities principally involve interaction between persons ... each person in civic engagement activities is a candidate for the term 'partner' and the many relationships between and among them can all be examined, evaluated, and studied". Since SNA provides researchers with methods to analyse social interactions and their corresponding quantifying aspects (Kenny et al 2006), we can extend SNA's scope to the South African context, and 
in particular the social relations between the country's HEls and their local third sector partners - NPOs in particular. Not only will this illuminate the workings of a particular interorganisational network, but it will also illustrate the place of HEls within such a network. If this place is of particular importance to the functioning of the overall network, we can argue that HEls play a significant role among third sector organisations. In turn, such an argument moves toward justifying the involvement of HEls in the third sector.

\subsection{Analysing interorganisational networks}

An analysis of the social network of a third sector organisation and an $\mathrm{HEI}$ can inform us on the interaction occurring within such a network. Such information can help determine the extent to which HEls are involved in their community, and subsequently such engagement initiatives can be evaluated. We can gain this information by looking either at the network's overall structure or by investigating the role of a network's individual members. Both these foci can shed light on the role of the HEI within a community.

A network's structure is subject to two properties, namely cohesion and shape (Borgatti, Mehra, Brass \& Labianca 2009). Cohesion refers mainly to the number of connections within a network, but can also include properties such as density and fragmentation (Blanchet \& James 2012): the denser a network and the higher its levels of cohesion, the tighter its connections among individual actors. A high degree of cohesion, for example, indicates that contact exists among most of the network actors. On the other hand, a loose-knit network attests to a lesser degree of contact. Close- and loose-knit networks have both advantages and disadvantages. Whereas a close-knit network allows for a wide and free distribution of information, ideas and resources, a loose-knit network grants greater privacy to its members. Contrary to the high solidarity among the members of a close-knit network, a loose-knit network is less likely to mobilise collective support. A loose-knit network's members might, however, be more likely to accept new ideas from outside sources and make the subsequent changes to their network (Hill 2002).

In addition to cohesion, we can also derive relational information from a network's particular shape. In this regard, shape denotes the overall distribution of ties and in the process distinguishes between core and peripheral actors (Borgatti et al 1990). The latter actors would be those who exist on the outskirts and are connected with the rest of the network by means of weak ties. With such information at hand, HEls and their third sector partners can make the necessary adjustments toward a better functioning interorganisational network. Granovetter's (1973) seminal theory on 


\section{EXPLORING THE CONNECTEDNESS OF THE THIRD SECTOR AND HIGHER EDUCATION INSTITUTIONS}

strong and weak ties depicts strong ties as being 'clumsy', since they merely recycle the same information. In contrast, weak ties, as Borgatti et al (2009:893) explain, can easily 'be unconnected' from the rest of the network and thus open the network up to novel information. Therefore, understanding where a network's weak ties are might grant an actor access to new resources. Such information can be especially pertinent to young third sector organisations eager to establish their place within a community and network.

A second focus of analysis pertains to the actors within a network. Actors can either be in the core of the network, thus highly connected, or peripheral due to loose connections with actors. The position of actors within the network also influences the flow of information. Some actors act as 'knowledge brokers', obstructing or constructing knowledge flow within a network (Blanchet \& James 2012). SNA and its measurements can capture such positions, answering questions such as "who is important in the network, who makes things happen in the network or holds the network together in times of distress?" (Prell 2012:96). By knowing which actors are at the core of a network, organisations can recognise their role vis-à-vis the overall network and subsequently provide them with the necessary support.

One approach to analysing an individual's role within a network is through the concept of centrality. First developed by Freeman (1979), this concept unpacks, among other things, an actor's degree of centrality to illuminate that actor's function within the network. According to Prell (2012), measures of centrality are among the first, and consequently the most popular, attempts of social network analysts to better understand the place of individual actors within a network. Consequently, social network analysts have devised a great array of degree measures, all contributing to the analysis of social networks. These include, among others, measure of degree centrality, betweenness, closeness, and eigenvector. Degree centrality, in particular, "is the number of ties of a given type that a node (actor) has" (Borgatti, Everett \& Johnson 2013:165). A high degree of centrality denotes a greater access to resources, information, and even power over the network (Moore et al 2003). Knowing more about the positions of individual actors, especially those that channel resources, sheds light on a network's overall functioning and levels of knowledge sharing. SNA and measures such as degree centrality can help us come closer to such information.

\section{THE CASE STUDY}

Case studies are highly appropriate to analyse and subsequently understand the dynamics of social networks (Provan et al 2004). It was therefore decided to use 
a case study to illustrate how SNA highlights the interaction between third sector organisations and an HEl. The University of the Free State's School of Nursing staff and three community partners, all of whom are active within the same geographical area, were chosen for the study. For the purpose of this chapter this interorganisational network will be referred to as the NPO-HEI network.

The UFS has thus far launched numerous community partnerships to fulfil its community engagement commitment. These commitments came about in response to the Ministry of Higher Education's 1997 Education White Paper 3 (RSA DoE 1997) that urges $\mathrm{HEls}$ to become more invested in their surrounding communities. In addition to individual community projects and resource allocation, the community engagement commitment of the UFS also entails the translation of social and civic responsibility into the teaching and learning facet of its different academic programmes. The pedagogy of service learning has been one of the UFS's main mechanisms for accomplishing this objective. One such example is the School of Nursing's postgraduate module entitled Nursing Education Practical. Typically, students enrolled in this module are registered nurses who wish to further their career in the field of higher education. Students work alongside community partners in the learning environments of pre-registered nursing students to develop nursing curricula in response to immediate community needs and challenges. These nursing education students are also expected to perform clinical demonstrations to preregistered nursing students and community health workers. To realise its teaching and learning outcomes, this module requires a community-based component. In this regard, partnerships between the UFS and third sector organisations (NPOs) are of vital importance. One might argue that these partnerships bring the pedagogy of service learning, and ultimately the UFS's community engagement commitments, to fruition.

The coordinators of the nursing education module work closely with three local NPOs. Concerned with the social welfare of the community, these NPOs are for the most part active within the Heidedal suburb of Bloemfontein. This includes caring for abandoned children, attending to the social needs of vulnerable children, and supplying home-based care to the ill and elderly.

For the purpose of our case study, the UFS and these NPOs form a complete network with a predetermined network boundary. Unlike an ego-network interested in the immediate personal networks surrounding each research participant, a complete network refers to an entire set of actors, in this case organisations, and the ties linking them together. A network boundary refers to "the boundary around a set of actors that the researcher deems to be the complete set of actors for the network study" 


\section{EXPLORING THE CONNECTEDNESS OF THE THIRD SECTOR AND HIGHER EDUCATION INSTITUTIONS}

(Prell 2012:66). Depending on the study's parameters, the researcher establishes the boundary of his/her study. The nursing education module is not the School of Nursing's only service learning module, and only one of several UFS service learning modules. Furthermore, the UFS's list of community partners far exceeds the three NPOs used in this study. Nevertheless, it was decided to use this particular academic module and its corresponding NPO partners as a case study as it supplied both a network active within a bounded geographic area and a network size adequate for the scope of the research reported in this chapter.

\subsection{Methodology}

The SNA was used to understand both the overall structure of an NPO-HEI network and the degree of interaction between the members of the network's respective organisations. This pertains more to the interaction between organisations than the networking happening within each individual organisation. Additionally, it was decided whether and to what extent the organisations share resources among one another. This includes the network's tendency to share knowledge among its different organisations. Since issues related to resources and interorganisational communication mostly concern the administrative rather than the functional facet of organisations, only the managerial staff $(\mathrm{N}=11)$ within the network was recruited. This included the directors, financial managers, secretaries and/or communication/ liaison officers of the organisations. Similarly, with regard to the university, only the coordinators and overseeing department head $(\mathrm{N}=3)$ of the nursing education module participated in the study.

I obtained the data by means of a concise electronic survey. The survey consisted of two sections: the first asked for demographic detail, such as age, gender, and the number of years each individual had been working at his/her respective organisation. The second section covered aspects related to the NPO-HEl social network. With this section I first wanted to gauge the degree of collaboration among network members, ${ }^{1}$ and next to establish the extent to which resources are distributed within the NPO-HEI network in question. In this regard, resources refer to

1 Question 5: Approximately how often, if at all, do you collaborate with each of the following individuals on matters related to your organisation(s)/institution(s)? 
knowledge individuals might have on funding prospects ${ }^{2}$ and personal development opportunities such as workshops. ${ }^{3}$

Prior to distribution, I pre-tested the survey on individuals who were familiar with the NPO-HEl context. This was to ensure the clarity of the survey questions. To answer each question, participants were presented with an alphabetic list of all 14 participating actors. In reference to different topics, participants were asked to rate how frequently they interacted with every individual on the list. The participants could choose between every day, once a week, once every six months, maybe once a year at a workshop, I know this person but we never talk about this issue or I do not know this person.

I used UCINET, an SNA software tool designed by Borgatti, Everett and Freeman (2002), to analyse the data obtained from the electronically distributed surveys. This analysis included the calculation of the network's degree of centrality measures (see Figures 10.2 and 10.4.) The social network graphs were constructed with the help of Netdraw (Borgatti 2002), visualising software bundled with UCINET.

Network members from the same organisations were assigned the same sign and colour. To protect the identity and privacy of the NPOs and their staff, I used the letters $A, B$ and $C$ to represent their respective organisations. The letter $U$ represents the participants from the university. Additionally, I assigned numbers to each of the NPO-HEl network's individual members. For example, organisation A's members were labelled A1, A2 and A3. These letters and numbers were assigned randomly and do not denote any hierarchical or nominal value. The size of the member's individual signs, however, represents his/her degree of centrality. For example, with a total of 13 ties, member U2 (see Figure 10.1) had the highest degree of centrality in the NPO-HEl collaboration network and consequently the biggest sign.

\subsection{Results and discussion}

In the following section and in reference to Figures 10.1, 10.3 and 10.4, I elaborate on the nature of the NPO-HEI network with regard to its degree of collaboration and level of knowledge sharing. I focus specifically on the network's structure and the centrality of the network's individual members.

2 Question 7: Approximately how often, if at all, do you talk with each of the following individuals about funding and/or grant opportunities that are available to your organisation(s)/ institution(s)?

3 Question 8: Approximately how often, if at all, do you inform each of the following individuals about workshops and/or personal development opportunities that would professionally benefit them and their organisation(s)/institution(s)? 


\section{EXPLORING THE CONNECTEDNESS OF THE THIRD SECTOR AND HIGHER EDUCATION INSTITUTIONS}

\subsubsection{Collaboration}

Figure 10.1 captures the participants' responses with regard to their perception of the level of collaboration occurring within the NPO-HEI network. From the structure of this network - that is, the density of the ties, the distribution of the individual actors, and the shape of the overall network - we can regard organisation $A$ as being rather peripheral in relation to the other organisations. In comparison with organisations $B$ and $C$, organisation $A^{\prime}$ s primary form of interaction occurs internally. According to Prell (2012), peripheral actors can move power away from more centrally located actors. This can be positive, causing power to be more equally distributed throughout the network. On the other hand, collaborative actions toward a common goal might suffer due to outlying network members. Judging by the limited number of ties connecting organisation $A$ to other actors, we can also argue that this organisation is connected rather loosely to the rest of the network. This can either be read as independence from to the rest of the network or the presence of Granovetter's reference to weak ties (see discussion above).

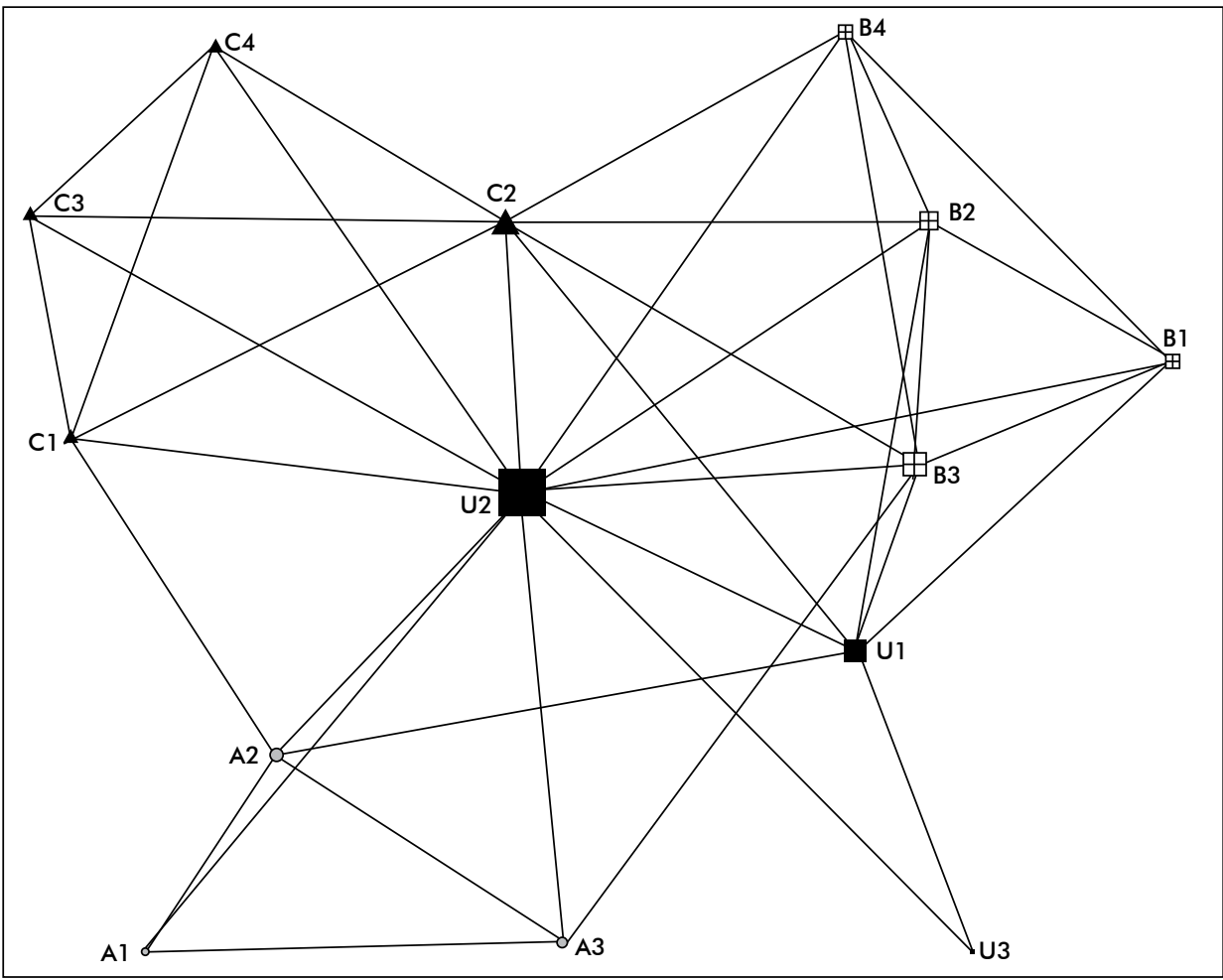

FIGURE 10.1

NPO-HEl collaboration network 
As far as individual actors are concerned, one can safely say that actors U2, C2, U1 and B3 are essential to the network's level of collaboration. These actors have the highest measure of degree centrality with 13, 8 and 7 respectively (see matrix in Table 10.1). Organisation $A$ is the most peripheral with regard to the rest of the network and organisations $B$ and $C$ are only connected through actor C2. Possibly this places pressure on actor C2, because without him/her the network will deteriorate, causing lower levels of collaboration. Overall, actors U2 and C2 play central roles in keeping the network together and, due to their central positions within the network, allow for the distribution of information and resources.

TABLE 10.1 UCINET degree centrality matrix for NPO-HEI collaboration (symmetrised)

\begin{tabular}{|r|r|r|r|r|}
\multicolumn{2}{c|}{} & \multicolumn{1}{c}{1} & 2 & 3 \\
\cline { 4 - 5 } \multicolumn{2}{c|}{} & Degree & NrmDegree & Share \\
\hline 4 & U2 & 13.000 & 100.000 & 0.167 \\
\hline 10 & C2 & 8.000 & 61.538 & 0.103 \\
\hline 2 & U1 & 7.000 & 53.846 & 0.090 \\
\hline 8 & B3 & 7.000 & 53.846 & 0.090 \\
\hline 7 & B2 & 6.000 & 46.154 & 0.077 \\
\hline 5 & C1 & 5.000 & 38.462 & 0.064 \\
\hline 6 & A2 & 5.000 & 38.462 & 0.064 \\
\hline 9 & B4 & 5.000 & 38.462 & 0.064 \\
\hline 33 & B1 & 5.000 & 38.462 & 0.064 \\
\hline 14 & C4 & 4.000 & 30.769 & 0.051 \\
\hline 12 & A3 & 4.000 & 30.769 & 0.051 \\
\hline 13 & C3 & 4.000 & 30.769 & 0.051 \\
\hline 1 & A1 & 3.000 & 23.077 & 0.038 \\
\hline 11 & U3 & 2.000 & 15.385 & 0.026 \\
\hline
\end{tabular}

DESCRIPTIVE STATISTICS

\begin{tabular}{|c|c|c|c|c|}
\hline & 1 & 2 & 3 \\
\hline & & Degree & NrmDegree & Share \\
\hline 1 & Mean & 5.571 & 42.857 & 0.071 \\
\hline 2 & Std Dev & 2.583 & 19.872 & 0.033 \\
\hline 3 & Sum & 78.000 & 600.000 & 1.000 \\
\hline 4 & Variance & 6.673 & 394.880 & 0.001 \\
\hline 5 & SSQ & 528.000 & 31242.604 & 0.087 \\
\hline 6 & MCSSQ & 93.429 & 5528.318 & 0.015 \\
\hline 7 & Euc Norm & 22.978 & 176.756 & 0.295 \\
\hline 8 & Minimum & 2.000 & 15.385 & 0.026 \\
\hline 9 & Maximum & 13.000 & 100.000 & 0.167 \\
\hline 10 & $\mathrm{~N}$ of $\mathrm{Obs}$ & 14.000 & 14.000 & 14.000 \\
\hline
\end{tabular}




\section{EXPLORING THE CONNECTEDNESS OF THE THIRD SECTOR AND HIGHER EDUCATION INSTITUTIONS}

Since U2 and U1 are HEl actors we can clearly see that the university plays an important role in this particular network. If the HEl actors were to be taken out (see Figure 10.2), it is clear that this would affect the rest of the network adversely. Since the involvement of $U 2$ and $U 1$ in this network is directly linked to the coordination of a service learning module, it is safe to say that the pedagogy of service learning does serve as an effective "entry point for community engagement" (Lazarus et al 2008:64).

A commonly held claim against $\mathrm{HEl}$-third sector partnerships is that "such partnerships are assumed to be in place, yet what is happening on the ground may not in fact represent a quality partnership" (Netshandama 2010:70). As is evident from our case study, SNA can assist researchers in putting such claims to the test.

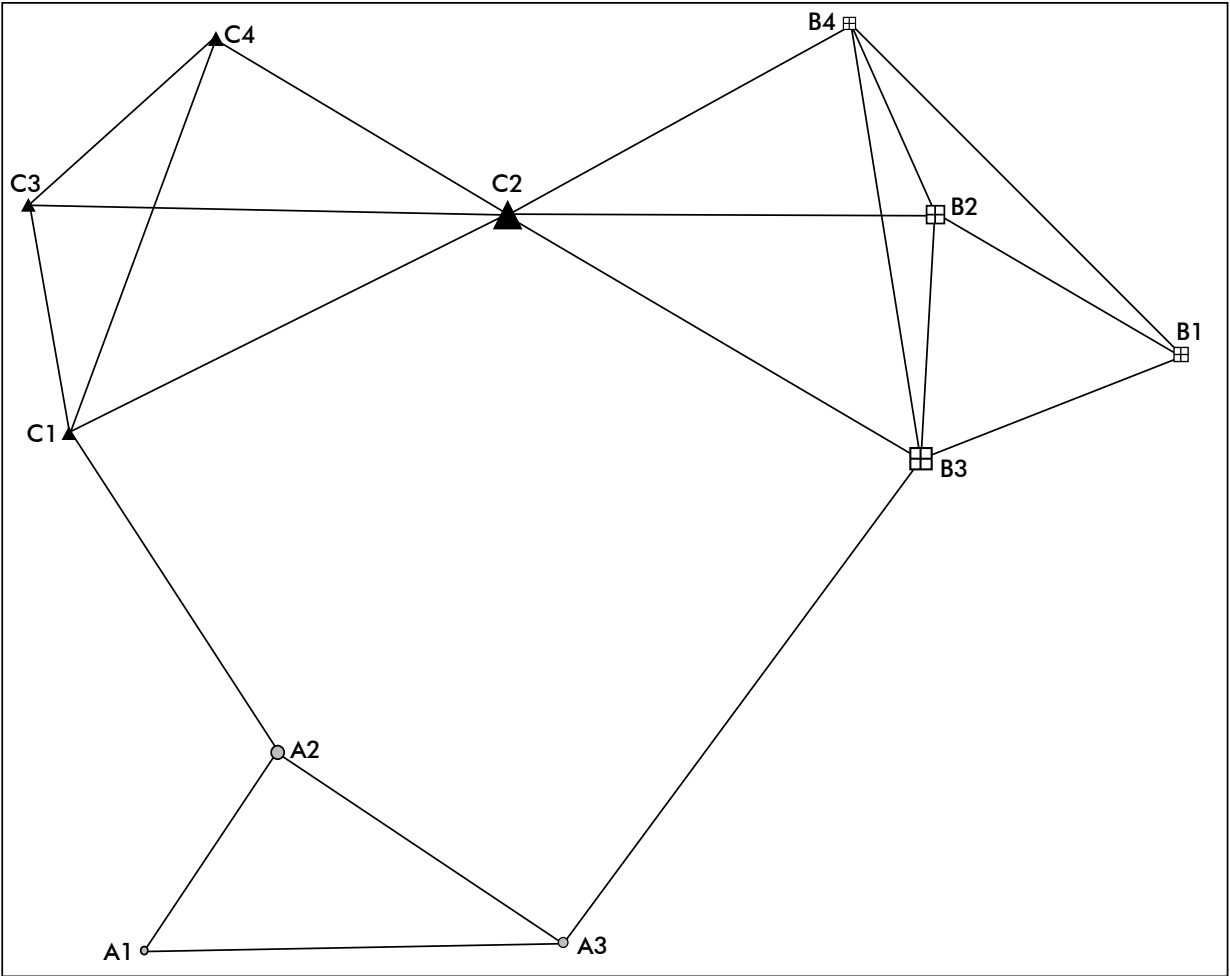

FIGURE 10.2

NPO-HEI collaboration network without university actors

\subsubsection{Knowledge sharing}

The sharing of resources, such as knowledge on funding or professional development, is an important function of social networking. In reference to NPOs in particular, Eng et al (2011:1106) maintain that organisations can "benefit from interaction with 


\section{CHAPTER $10 \cdot$ CLOETE}

members in the network communities by gaining necessary knowledge and expertise to improve [their] operational competence".

To understand the degree and nature of knowledge sharing within our NPO-HEI network, it was necessary to differentiate between different types of knowledge. In one case study, participants were asked to first rate their level of interaction as far as the sharing of knowledge on funding resources were concerned and then to provide more general workshop information. As figures 10.3 and 10.4 illustrate, one can see a slight difference between the two types of knowledge sharing. Not surprisingly though, the network on sharing funding resources (Figure 10.3) is less dense than that of workshop information (Figure 10.4). This denotes a lesser degree of interaction among organisations. That being said, and in contrast to the other organisations and their actors, organisation B's actors are more centrally located. Even though the literature informs us that knowledge sharing is one of the key qualities of social networks, third sector organisations are particularly wary regarding the amount of knowledge they share about funding resources. This is most likely due to the limited number of such resources available (Eng et al 2011 1). Responses to Question 7 that pertains to knowledge sharing about funding and/or grant opportunities yielded networking results as shown in Figure 10.3 and Table 10.2.

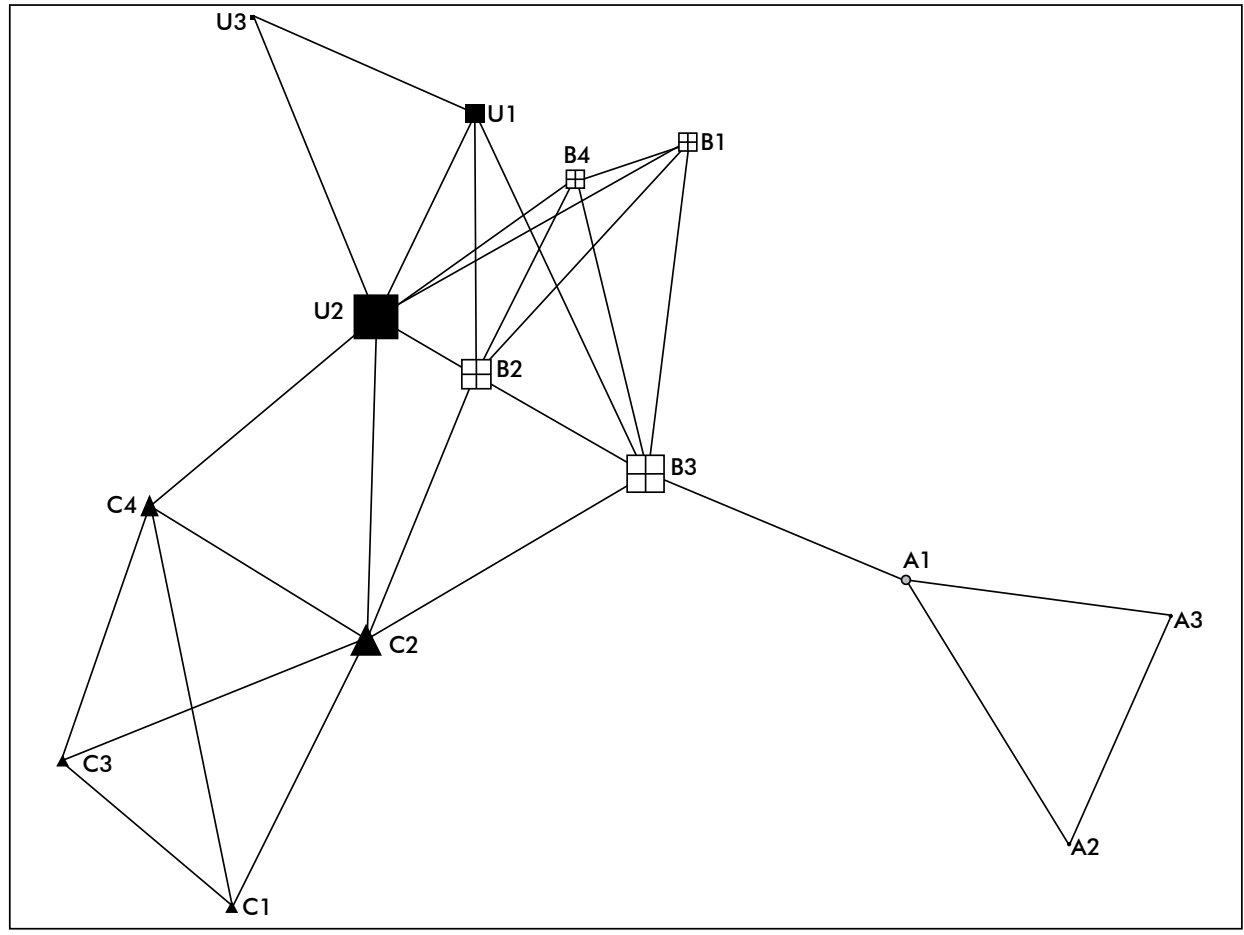

FIGURE 10.3

NPO-HEl knowledge sharing network (funding and grant opportunities) 


\section{EXPLORING THE CONNECTEDNESS OF THE THIRD SECTOR AND HIGHER EDUCATION INSTITUTIONS}

TABLE 10.2 UCINET degree centrality matrix for NPO-HEI knowledge sharing (funding) (symmetrised)

\begin{tabular}{|r|c|c|c|c|}
\multicolumn{2}{|c|}{} & \multicolumn{1}{c|}{1} & 2 & 3 \\
\hline \multicolumn{2}{|c|}{} & Degree & NrmDegree & Share \\
\hline 4 & U2 & 8.000 & 61.538 & 0.138 \\
\hline 8 & B3 & 7.000 & 53.846 & 0.121 \\
\hline 10 & C2 & 6.000 & 46.154 & 0.103 \\
\hline 7 & B2 & 6.000 & 46.154 & 0.103 \\
\hline 2 & U1 & 4.000 & 30.769 & 0.069 \\
\hline 14 & C4 & 4.000 & 30.769 & 0.069 \\
\hline 9 & B4 & 4.000 & 30.769 & 0.069 \\
\hline 3 & B1 & 4.000 & 30.769 & 0.069 \\
\hline 5 & C1 & 3.000 & 23.077 & 0.052 \\
\hline 13 & C3 & 3.000 & 23.077 & 0.052 \\
\hline 1 & A1 & 3.000 & 23.077 & 0.052 \\
\hline 12 & A3 & 2.000 & 15.385 & 0.034 \\
\hline 6 & A2 & 2.000 & 15.385 & 0.034 \\
\hline 11 & U3 & 2.000 & 15.385 & 0.034 \\
\hline
\end{tabular}

DESCRIPTIVE STATISTICS

\begin{tabular}{|c|c|c|c|c|}
\hline & 1 & 2 & 3 \\
\hline & & Degree & NrmDegree & Share \\
\hline 1 & Mean & 4.143 & 31.868 & 0.071 \\
\hline 2 & Std Dev & 1.846 & 14.201 & 0.032 \\
\hline 3 & Sum & 58.000 & 446.154 & 1.000 \\
\hline 4 & Variance & 3.408 & 201.666 & 0.001 \\
\hline 5 & $S S Q$ & 288.000 & 17041.420 & 0.086 \\
\hline 6 & MCSSQ & 47.714 & 2823.331 & 0.014 \\
\hline 7 & Euc Norm & 16.971 & 130.543 & 0.293 \\
\hline 8 & Minimum & 2.000 & 15.385 & 0.034 \\
\hline 9 & Maximum & 8.000 & 61.538 & 0.138 \\
\hline 10 & $\mathrm{~N}$ of $\mathrm{Obs}$ & 14.000 & 14.000 & 14.000 \\
\hline
\end{tabular}

Responses to Question 8 that pertains to sharing of information about workshops and/or personal development opportunities yielded results as depicted in Figure 10.4 and Table 10.3. 


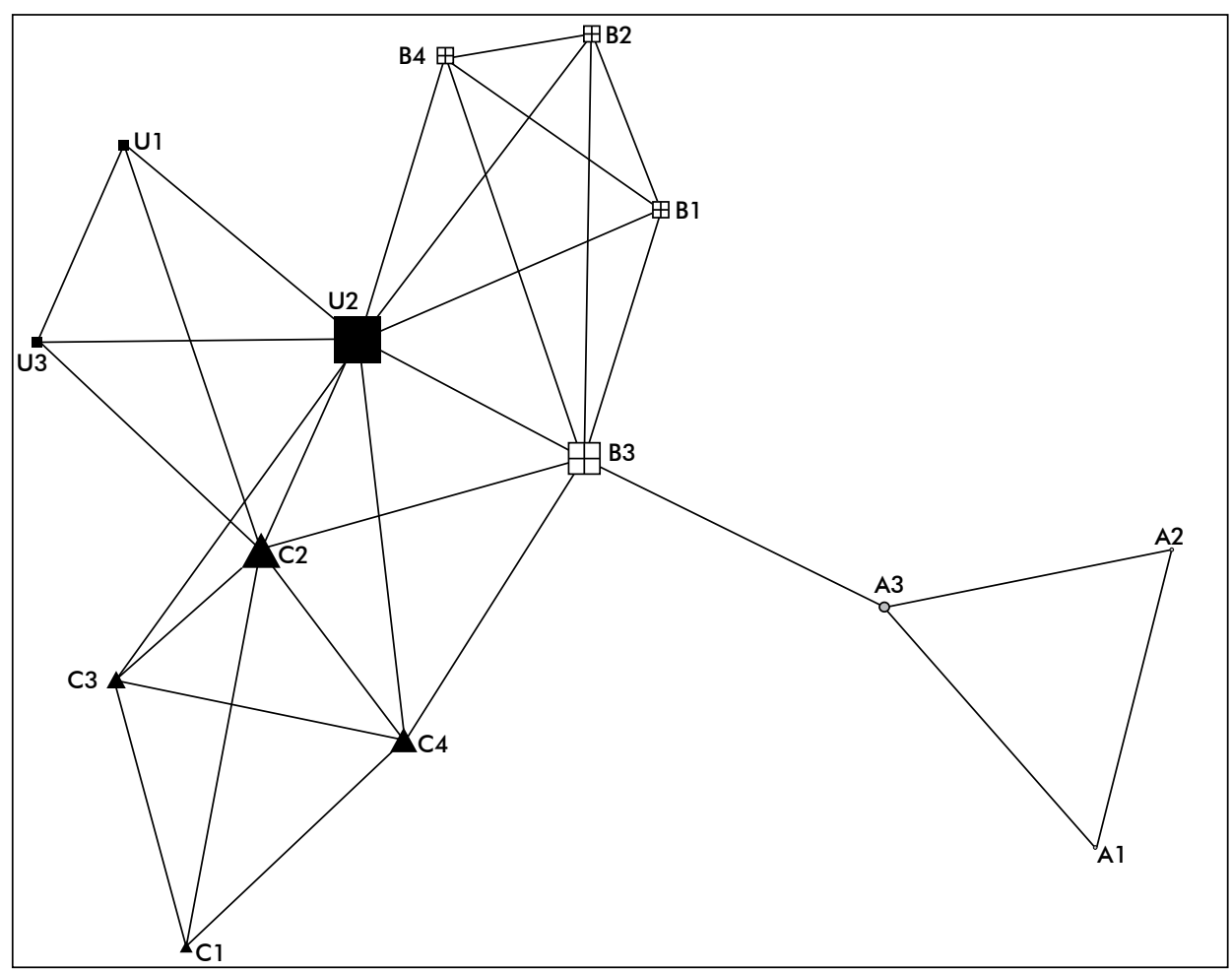

FIGURE 10.4 NPO-HEI knowledge sharing network (workshop and personal development information)

TABLE 10.3 UCINET degree centrality matrix for NPO-HEI knowledge sharing (workshop information) (symmetrised)

\begin{tabular}{|r|c|c|c|c|}
\multicolumn{2}{c}{} & 1 & 2 & 3 \\
\multicolumn{2}{c|}{} & Degree & NrmDegree & Share \\
\hline 4 & U2 & 9.000 & 69.231 & 0.150 \\
\hline 10 & C2 & 7.000 & 53.846 & 0.117 \\
\hline 8 & B3 & 7.000 & 53.846 & 0.117 \\
\hline 14 & C4 & 5.000 & 38.462 & 0.083 \\
\hline 9 & B4 & 4.000 & 30.769 & 0.067 \\
\hline 7 & B2 & 4.000 & 30.769 & 0.067 \\
\hline 13 & C3 & 4.000 & 30.769 & 0.067 \\
\hline 3 & B1 & 4.000 & 30.769 & 0.067 \\
\hline 5 & C1 & 3.000 & 23.077 & 0.050 \\
\hline 2 & U1 & 3.000 & 23.077 & 0.050 \\
\hline 11 & U3 & 3.000 & 23.077 & 0.050 \\
\hline 12 & A3 & 3.000 & 23.077 & 0.050 \\
\hline 6 & A2 & 2.000 & 15.385 & 0.033 \\
\hline 1 & A1 & 2.000 & 15.385 & 0.033 \\
\hline
\end{tabular}




\section{EXPLORING THE CONNECTEDNESS OF THE THIRD SECTOR AND HIGHER EDUCATION INSTITUTIONS}

\begin{tabular}{|c|c|c|c|c|}
\hline & 1 & 2 & 3 \\
\hline & & Degree & NrmDegree & Share \\
\hline 1 & Mean & 4.286 & 32.967 & 0.071 \\
\hline 2 & Std Dev & 1.979 & 15.227 & 0.033 \\
\hline 3 & Sum & 60.000 & 461.538 & 1.000 \\
\hline 4 & Variance & 3.918 & 231.856 & 0.001 \\
\hline 5 & SSQ & 312.000 & 18461.537 & 0.087 \\
\hline 6 & MCSSQ & 54.857 & 3245.985 & 0.015 \\
\hline 7 & Euc Norm & 17.664 & 135.873 & 0.294 \\
\hline 8 & Minimum & 2.000 & 15.385 & 0.033 \\
\hline 9 & Maximum & 9.000 & 69.231 & 0.150 \\
\hline 10 & $\mathrm{~N}$ of $\mathrm{Obs}$ & 14.000 & 14.000 & 14.000 \\
\hline
\end{tabular}

In both networks, organisations $A$ and $C$ are peripheral. Even though actor $C 2$ was central to the collaboration network, he/she is less involved as far as resource sharing goes. Even though not as prominent as actor C2, actor U2 is also less involved. In both networks actor U2 still has the highest degree centrality (see the matrices in Tables 10.2 and 10.3), meaning that he/she is still pertinent to the overall network and a prominent knowledge broker.

A position with high degree centrality is strategic, especially as far as resource sharing is concerned (Prell 2012). Actors in such positions can channel the flow of resources from one organisation to another, but on the other hand, if actors abuse their position of power they can obstruct the flow of resources from the rest of their own organisation as well as from the rest of the network. In both knowledge sharing networks actors B2 and B3 are in such strategic positions. If they wish, they can obstruct the flow of knowledge from or to organisation A. Knowing about the position of actors within a network can allow organisations to 'connect better', that is, position themselves more closely to resource-rich actors.

\section{CONCLUSION}

Universities the world over are developing smart partnerships with their communities ... however, all too often, there is a tendency in academia to use the idea of engagement as an 'aerosol' term, sprayed over any interaction between a $\mathrm{HEI}$ and the community to give the relationship a politically correct facelift (Netshandama 2010:70).

To what extent do the card swopping third sector workers, mentioned at the beginning of this chapter, 'keep in touch'? Furthermore, to what extent do universities, which so eagerly engage in community partnerships, honour such commitments and become 
actively intertwined in the interorganisational networks of the third sector? As Buys and Bursnall (2007) argue, seeing such partnership commitments through is not only vital to community growth, but allows organisations to reach more people without duplicating the same initiatives. Moreover, well-functioning partnerships allow the free flow of resources to reach an even greater population; therefore organisations should network, as this can have a positive impact on their effectiveness.

Social networks are central to society. Judging from the amount of electronic social networking captivating society on a daily basis, Castells (2000) is not far off the mark when stating that we live in a network society. In this regard we should not hesitate to incorporate networks into our research agendas, questions and analysis. As I have argued throughout this chapter, methods such as SNA can help us unpack the intricate web of social networks. But, more importantly, and in line with the overarching theme of this book, SNA can provide us with an alternative tool to investigate the relationship between third sector organisations and higher education institutions. In the process, we can determine whether such engagements are merely of the sprayed on superficial type, or whether they are deeply embedded in existing networks, committed to communal needs and social well-being.

\section{REFERENCES}

Blanchet K \& James P. 2012. How to do (or not to do) ... a social network analysis in health systems research. Health Policy and Planning, 27(5):438-46.

Borgatti SP. 2002. NetDraw: Graph visualization software. Harvard, MA: Analytical Technologies.

Borgatti SP, Everett MG \& Freeman LC. 2002. UCINET for Windows: Software for social network analysis. Harvard, MA: Analytical Technologies.

Borgatti SP, Mehra A, Brass DJ \& Labianca G. 2009. Network analysis in the social sciences. Science, 323(5916):892-895.

Borgatti S, Everett MG \& Johnson JC. 2013. Analyzing social networks. Los Angeles: Sage.

Bringle R, Clayłon P \& Price M. 2009. Partnerships in service learning and civic engagement. Partnerships: A Journal of Service Learning \& Civic Engagement, 1 (1):1-20.

Buys N \& Bursnall S. 2007. Establishing university-community partnerships: Processes and benefits. Journal of Higher Education Policy and Management, 29(1):73-86.

Castells M. 2000. The Information Age: Economy, society and culture, Volume 1: The rise of the network society. 2nd Edition. Oxford: Blackwell.

Eng TY, Liu CYG \& Sekhon YK. 2011. The role of relationally embedded network ties in resource acquisition of British nonprofit organizations. Nonprofit and Voluntary Sector Quarterly, 41 (6): 1092-1115.

Ennis $G$ \& West D. 2012. Using social network analysis in community development practice and research: A case study. Community Development Journal, 48(1):40-57. 


\section{EXPLORING THE CONNECTEDNESS OF THE THIRD SECTOR AND HIGHER EDUCATION INSTITUTIONS}

Fisher WF. 1997. Doing good? The politics and antipolitics of NGO practices. Annual Review of Anthropology, 26(1):439-464.

Freeman LC. 1979. Centrality in social networks. Social Networks, 19:157-191.

Galaskiewicz J, Bielefeld W \& Dowell M. 2006. Networks and organizational growth: A study of community based nonprofits. Administrative Science Quarterly, 51:337-380.

Gilchrist A. 2004. The well-connected community: A networking approach to community development. Bristol: Policy Press.

Granovetter M. 1973. The strength of weak ties. American Journal of Sociology, 78:1360-1380.

Guo C \& Acar M. 2005. Understanding collaboration among nonprofit organizations: Combining resource dependency, institutional, and network perspectives. Nonprofit and Voluntary Sector Quarterly, 34(3):340-361.

Hill M. 2002. Network assessments and diagrams: A flexible friend for social work practice and education. Journal of Social Work, 2(2):233-254.

Johnson JA, Honnold JA \& Stevens FP. 2010. Using social network analysis to enhance nonprofit organizational research capacity: A case study. Journal of Community Practice, 18(4):493-512.

Kapucu N. 2005. Interorganizational coordination in dynamic context: Networks in emergency response management. Connections, 26(2):33-48.

Kenny DA, Kashy DA \& Cook WL. 2006. Social network analysis. In: DA Kenny, DA Kashy \& WL Cook. Dyadic data analysis. New York: Guilford Press. 316-336.

Lazarus J, Erasmus M, Hendricks D, Nduna J \& Slamat J. 2008. Embedding community engagement in South African higher education. Education, Citizenship and Social Justice, $3(1): 57-83$

Muller, C. 2008. Focus: Music of South Africa. New York: Routledge.

Moore S, Eng E \& Daniel M. 2003. International NGOs and the role of network centrality in humanitarian aid operations: A case study of coordination during the 2000 Mozambique floods. Disasters, 27(4):305-318.

Netshandama V. 2010. Quality partnerships. International Journal of Community Research and Engagement, 3:70-87.

Prell C. 2012. Social network analysis: History, theory and methodology. Los Angeles: Sage.

Provan KG, Fish A \& Sydow J. 2007. Interorganizational networks at the network level: A review of the empirical literature on whole networks. Journal of Management, 33(3):479-516.

Provan KG, Veazie MA, Staten LK \& Teufel-Shone NI. 2005. The use of network analysis to strengthen community partnerships. Public Administration Review, 65(5):603-613.

Provan, K G. 2004. Cooperation and compromise: A network response to conflicting institutional pressures in community mental health. Nonprofit and Voluntary Sector Quarterly, 33(3):489-514.

RSA DoE (Republic of South Africa. Department of Education). 1997. Education White Paper 3: Programme for the Transformation of Higher Education. Pretoria: RSA DoE

Uzzi B. 1997. Social structure and competition in interfirm networks: The paradox of embeddedness. Administrative Science Quarterly, 42:35-67. 